\title{
Improving the thermal properties of fluoroelastomer (Viton GF-600S) using acidic surface modified carbon nanotube
}

\author{
Javad Heidarian ${ }^{1,2 \star}$, Aziz Hassan ${ }^{1}$ and Nor Mas Mira Abd Rahman ${ }^{1}$ \\ ${ }^{1}$ Polymer and Composite Materials Research Laboratory, Department of Chemistry, \\ University of Malaya - UM, Kuala Lumpur, Malaysia \\ ${ }^{2}$ Polymer and Science Technology Division, Research Institute of Petroleum Industry - RIPI, Tehran, Iran \\ *heidarianj@um.edu.my; heidarianj@yahoo.com
}

\begin{abstract}
Acid surface modified carbon nanotube (MCNT)-, Carbon nanotube (CNT)-filled fluoroelastomer (FE) and unfilled-FE were prepared (MCNT/FE, CNT/FE and FE). The compounds were subjected to thermogravimetric analysis (TGA) and heat air aging, and characterized by Energy Dispersive X-Ray (EDX). Results showed that MCNT improved the thermal properties of $\mathrm{FE}$, resulting in a larger amount of $\mathrm{FE}$ and char remaining in the temperature range of $400-900{ }^{\circ} \mathrm{C}$ relative to unfilled FE and CNT/FE. The MCNT/FE TGA curve shifted towards higher temperatures compared to CNT/FE and FE. The same results also revealed that higher percentages of FE were undegraded or less degraded especially near MCNT in the temperature range of $400-540{ }^{\circ} \mathrm{C}$. Energy Dispersive X-Ray (EDX) results indicated that the percentage of carbon and fluorine in the residue of TGA scans, up to $560^{\circ} \mathrm{C}$, of $\mathrm{MCNT} / \mathrm{FE}$ were the same as $\mathrm{CNT} / \mathrm{FE}$, and were higher than FE. EDX results of TGA residue (run up to $900^{\circ} \mathrm{C}$ ) showed that most of the undegraded FE, which was not degraded at temperatures below $560^{\circ} \mathrm{C}$, was degraded from $560{ }^{\circ} \mathrm{C}$ to $900{ }^{\circ} \mathrm{C}$ in both $\mathrm{MCNT} / \mathrm{FE}$ and CNT/FE, with the char in MCNT/FE being more than that in CNT/FE. EDX analysis of thermal aged specimens under air showed that, with increasing aging time, a greater percentage of $\mathrm{C}, \mathrm{O}$ and $\mathrm{F}$ was lost from the surface of filler/FE and FE. The order of element loss after 24 hour aging time was: MCNT/FE $>$ FE $>$ CNT/FE.
\end{abstract}

Keywords: nanocomposites, fluoroelastomer, acidic surface modified, carbon nanotube, thermal properties, thermal aging.

\section{Introduction}

Viton is a synthetic rubber and fluoroelastomer (FE). Viton ${ }^{\circledR}$ GF-600S is a terpolymer of hexafluoro-propylene, vinylidene fluoride and tetra-fluoroethylene with a cure site monomer. It is a peroxide cure, $70 \%$ fluorine $\mathrm{FE}^{[1,2]}$.

Normally, in the formulation of FE, carbon black (CB) is used. Replacing CB with surface modified CNT (MCNT) is expected to improve the thermal properties of FE, which is very effective in making O-rings especially for the oil and gas industries ${ }^{[3-5]}$. MCNT is also expected to improve thermo-oxidative degradation resistance of FE composites when subjected to thermal aging conditioning in air.

MCNT improves the properties of fluoropolymers, such as crystallinity, electrical response, mechanical properties, viscoelastic behavior, etc, and therefore their thermal stability. This finding has been reported by a number of researchers and examples of literatures and the reasons for the changes in these properties are mentioned bellow.

It has been reported ${ }^{[3]}$ that the use of multi-walled carbon nanotubes (MWCNTs)-embedded in fluorinated rubber leads to a rubber nanocomposite with cellulation structure. This structure possesses improved thermal resistance. Pham et al. ${ }^{[4]}$ observed that with increased MWCNT loading in FE/MWCNTs nanocomposites, there is a steady increase in the decomposition temperature. Interactions between CNT and fluropolymers and the effect of surface area of $\mathrm{CNT}$ on the active interfacial area between them were investigated by a number of researchers, for examples:
A strong interaction between fluoropolymers and CNT was reported by He et al. ${ }^{[6]}$. The high aspect ratio of nanotubes also leads to a great increase in the active interfacial area between CNT and the fluoropolymer chain as reported by Chae et al. ${ }^{[7]}$. An energetic relationship between the surface of CNT and fluoropolymer has been reported by Levi et al. ${ }^{[8]}$.

CNT can change the mechanical and thermo-mechanical properties of polyvinilydienefluoride (PVDF) ${ }^{[9-11]}$ or the mechanical properties of polytetrafluoroethylene (PTFE) ${ }^{[12,13]}$. CNT can also change the degree of crystallinity of fluoropolymers and, therefore, their properties ${ }^{[14-16]}$.

Sementsov et al. ${ }^{[13]}$ reported that in nanocomposites of PTFE and MWCNT, the concentration and nature of oxygen containing MWCNT surface groups influences the strength parameters of the composite material. Wen et al. ${ }^{[17]}$ prepared (PVDF)/MWCNTs nanocomposites and studied the melt viscoelastic behavior of the composites. The results showed that PVDF/MWCNTs-g-OH (OH grafted) nanocomposites exhibit more significant solid-like behavior than PVDF/MWCNTs nanocomposites. Huang et al. ${ }^{[16]}$ showed that the interfacial interaction between the single walled carbon nanotubes (with hydroxyl groups) and PVDF has an effect on inducing crystallinity. The thermal stability of the PTFE composites is also enhanced by the presence of CNT as reported by Park et al. ${ }^{[18]}$. The temperatures recorded at maximum decomposition rate were affected by the type of surface modification of MWCNT. The thermograms 
for PTFE/MWCNT composites also shifted towards high temperatures.

Carabineiro et al. ${ }^{[19,20]}$ prepared CNT/PVDF composites using modified CNT samples. According to their research results, surface modifications of MWCNTs had an effect on the electrical response and the degree of crystallinity of the CNT/PVDF nanocomposites. Similarly, Xu and Yang ${ }^{[21]}$ prepared FE/MWCNT composite films using different surface modified CNTs. The better mechanical properties of CF4 plasma-modified CNT (FCNTs) composites over other studied CNTs is due to the better dispersion and enhanced chemical compatibility from introducing electron-rich fluorine atoms and also from hydrogen bonding.

The effect of thermal aging conditioning on FE in air and/or other environments were also verified by researchers. For example: the physical and chemical changes associated with degradation on the surface, near the surface and bulk of the FE seals in engine oil and additives were investigated by Smith et al. ${ }^{[22]}$. Degradation of these materials was reported to be limited to the near surface region of the samples to a depth of less than approximately $50 \mu \mathrm{m}$. The process resulted in the release of either $\mathrm{F}_{2}$ or HF.

Research on the verification of the effect of MCNT on the amount of residues in TGA runs of MCNT/FE nanocomposites is rather rare. In addition, comparison of the amount of residue in TGA runs of MCNT/FE, CNT/FE and $\mathrm{FE}$ detailing elemental composition is seldom published. Therefore, this investigation is unique in the sense that knowledge of the amount of residue and the composition of the elements in the residue gives an insight into the ability of MCNT to improve the thermal stability of CNT/FE and FE composites. Furthermore, the presence of elemental fluorine on the surface of MCNT/FE aged in air indicates whether MCNT can improve the resistance of the nanocomposites to thermo-oxidative degradation or not.

In the present work, MCNT was used as a filler for Viton $^{\circledR}$ GF-600S with the aim of improving the thermal stability and thermal aging resistance of FE. The thermal properties of the composites MCNT/FE were assessed by Thermogravimetric Analysis (TGA) and compared vis-à-vis those of CNT filled and unfilled FE composites in our previous work $^{[23]}$. Energy Dispersive X-Ray (EDX) was also used to characterize the elemental composition of the undegraded FE and char after TGA runs at temperatures below $900^{\circ} \mathrm{C}$. This was to ascertain whether the incorporation of MCNT could preserve more of the undegraded FE and char compared to CNT/FE or unfilled FE. EDX was also employed to verify the amount of $\mathrm{Zn}$ in the residue and to confirm a possible reaction with MCNT. Thermal aging conditioning in air together with EDX was also conducted to investigate the elemental composition of the surfaces of $\mathrm{MCNT} / \mathrm{FE}$ as a function of aging time.

\section{Experimental}

\subsection{Materials and compounding procedure}

The materials used were Viton GF-600S fluoroelastomer, FE; organic peroxide, Luperox 101 XL-45; acid surface modified carbon nanotube MCNT (TNMC8, -COOH Content:0.49wt \%), carbon nanotube CNT (TNM8) both with an outside diameter $>50 \mathrm{~nm}$, inside diameter:5-15nm, purity $>95 \%$, and length 10-20 $\mu \mathrm{m}$; zinc oxide; and triallylisocyanurate, TAIC supplied by ERIKS Sdn. Bhd. (Malaysia), Arkema Sdn. Bhd. (Malaysia), Chengdu Organic Chemicals Co. Ltd. (Chinese Academy of Sciences, China), Texchem Materials Sdn. Bhd. (Malaysia) and Liu Yang San Ji Chemical Trade Co. Ltd. (China) respectively. Three formulations were compounded, MCNT filled FE (MCNT/FE), CNT filled FE (CNT/FE) and unfilled FE (FE). The amounts of FE, organic peroxide, zinc oxide and TAIC in these compounds were 70.0, 2.1, 2.1 and $2.1 \mathrm{~g}$ respectively. For MCNT/FE and CNT/FE, $7.0 \mathrm{~g}$ filler was used.

Mixing FE with additives was done using a laboratory scale two roll mill with a roll temperature of $48^{\circ} \mathrm{C}$. FE in the above mentioned composition was supplied to the open roll. A uniform band was formed while three rolling cuts from each side of the mill were made, so that the polymer would be uniform and sufficiently warmed up. In the next stage, pre-blended $\mathrm{ZnO}$ and TAIC were added uniformly into the gum and three rolling cuts from each side of the mill were made. After setting the roll distance to $1.1 \mathrm{~mm}$, MCNT was then fed in. The compound was then tightly milled ten times. The roll distance was then adjusted to $1.1 \mathrm{~mm}$, and the peroxide was added and, after the final five to six rolled up end passes, the mixture was supplied to the open roll and sheeted. After 24 hours, re-milling was done with a roll temperature of $26^{\circ} \mathrm{C}$. A similar procedure was used for CNT/FE and FE.

\subsection{Curing and post curing}

Curing of the FE compound was done in molds $(15 \mathrm{~cm} \times 15 \mathrm{~cm} \times 1 \mathrm{~mm}$ and $18 \mathrm{~cm} \times 18 \mathrm{~cm} \times 2 \mathrm{~mm})$ in a heated press, at $177^{\circ} \mathrm{C}$ under a pressure of $10 \mathrm{MPa}$ for $7 \mathrm{~min}$. The post curing was done in an oven at $232{ }^{\circ} \mathrm{C}$ for two hours. The conditions for curing and post curing were recommended by the supplier.

\subsection{Thermal gravimetric analysis (TGA)}

25-35 mg of post-cured sample was subjected to TGA runs from room temperature to $900{ }^{\circ} \mathrm{C}$. This was carried out on a Perkin-Elmer thermal analysis system, model Pyris Diamond TG/DTA, at a scan rate of $20^{\circ} \mathrm{C} \cdot \mathrm{min}^{-1}$ and under nitrogen atmosphere of $20 \mathrm{ml} \cdot \mathrm{min}^{-1}$. In addition, TGA runs from room temperature to $560^{\circ} \mathrm{C}$ were carried out under the same conditions and then cooled to room temperature at a scan rate of $100^{\circ} \mathrm{C} \cdot \mathrm{min}^{-1}$. The same procedure was repeated with the temperature raised to $900^{\circ} \mathrm{C}$. The specimens were designated according to temperature, for example MCNT/FE-560 ${ }^{\circ} \mathrm{C}$, where the temperature after the specimen designation is the highest temperature of the TGA run. The same procedure was applied for 3.5-5 mg of pure MCNT.

\subsection{Thermal aging}

Thermal aging was carried out according to ASTM D-573 for 24,48 and 72 hours at $250{ }^{\circ} \mathrm{C}$. The samples $(5 \mathrm{~mm} \times 5 \mathrm{~mm} \times 2 \mathrm{~mm})$ were named FE, FE-24, FE-48 and FE-72, where the numbers following FE indicate the aging time in hours. Similar types of abbreviation were used for the MCNT/FE and CNT/FE aged samples. 


\subsection{Energy Dispersive X-Ray (EDX) and Field Emission Scanning Electron Microscopy (FESEM) image analyses}

EDX analysis was conducted using FESEM Philip XL-40 (UK) coupled with EDX. The residue obtained from the heating-cooling TGA scans was first applied on an aluminum stub using double sided copper tape (3M Company), then coated with gold for EDX elemental analysis to determine the elements of C, O, F, Si, Ca and $\mathrm{Zn}$.

Elemental compositions of the surfaces of the aged and unaged samples were obtained using EDX. Un-aged and aged samples, $5 \mathrm{~mm} \times 5 \mathrm{~mm} \times 2 \mathrm{~mm}$ in dimension, from the molded post cured FE, CNT/FE and MCNT/FE rubber sheets were used for EDX analysis. The major elements characterized were $\mathrm{C}, \mathrm{O}, \mathrm{F}$ and $\mathrm{Si}$. The surface images for some of the samples were obtained by FESEM. In FESEM imaging of MCNT/FE, the razor cut (cross-section) surface was used. Specimens for EDX and FESEM imaging analysis were applied on a copper tape and gold coated as mentioned above. However, for FESEM images of residues obtained from MCNT/FE-560 ${ }^{\circ} \mathrm{C}$ and MCNT/FE- $900{ }^{\circ} \mathrm{C}$, no gold coating was used.

\section{Results and Discussion}

\subsection{TGA}

Figure 1 shows the TGA thermograms of MCNT, FE, $\mathrm{MCNT} / \mathrm{FE}$ and CNT/FE. The extracted data from these plots are presented in Table 1 . In Table $1, \mathrm{~T}_{\text {onset }}, \mathrm{T}_{5 \%}, \mathrm{~T}_{10 \%}$ and $\mathrm{T}_{50 \%}$ are the onset temperature at which the compound started to lose weight (degrade), and temperatures at which the compound lost 5\%,10\% and 50\% weight respectively. $\mathrm{T}_{\text {onset }}, \mathrm{T}_{5 \%}, \mathrm{~T}_{10 \%}$ and $\mathrm{T}_{50 \%}$ increased for MCNT/FE compared to $\mathrm{CNT} / \mathrm{FE}$ and FE. As can be seen from Figure 1 the MCNT/FE curve shifted towards higher temperatures and the thermal stability improved compared to CNT/FE. Figure 2 shows the amount of this temperature (thermal stability) shift versus weight $\%$. Figure 2 shows that for the weight $\%$ of 100 to $40 \%$ the amount of thermal stability shift is almost constant $\left(\approx 10{ }^{\circ} \mathrm{C}\right)$. However, for weight $\%$ between $\approx 20$ to $40 \%$ the thermal stability shift increases suddenly $\left(\approx 20^{\circ} \mathrm{C}\right)$. This increase in thermal stability shift indicates that in this weight $\%$ range compared to the 100 to 40 weight $\%$ range, $\mathrm{FE}$ in $\mathrm{MCNT} / \mathrm{FE}$ showed more thermal stability improvement relative to $\mathrm{FE}$ in $\mathrm{CNT} / \mathrm{FE}$.

Pham et al. ${ }^{[4]}$, used a SEM micrograph of the ash residue collected after $90 \%$ degradation of the compound and showed that less or partial degradation of the polymer chains attached to the nanotubes occurred whereas extensive degradation occurred in the bulk. Therefore, the higher thermal stability shift for weight $\%$ between $\approx 20$ to $40 \%$ represents the part of FE which is near or attached to MCNT. All of the above mentioned results show that $\mathrm{FE}$ in $\mathrm{MCNT} / \mathrm{FE}$ is more

\begin{tabular}{ccccc}
\multicolumn{5}{c}{ Table 1. TGA thermal properties of FE, filler/FE and pure filler. } \\
\hline Specimen & $\mathbf{T}_{\text {Onset }}\left({ }^{\circ} \mathbf{C}\right)$ & $\mathbf{T}_{\mathbf{5 \%}}\left({ }^{\circ} \mathbf{C}\right)$ & $\mathbf{T}_{\mathbf{1 0} \%}\left({ }^{\circ} \mathbf{C}\right)$ & $\mathbf{T}_{\mathbf{5 0} \%}\left({ }^{\circ} \mathbf{C}\right)$ \\
\hline FE & 423.4 & 442.6 & 470.7 & 497.8 \\
$\mathrm{CNT} / \mathrm{FE}$ & 421.1 & 446.2 & 475.4 & 505.1 \\
$\mathrm{MCNT} / \mathrm{FE}$ & 433.1 & 457.7 & 485.4 & 513.7 \\
$\mathrm{MCNT}$ & 627.7 & 693.6 & 748.4 & - \\
$\mathrm{CNT}$ & 594.5 & 640.2 & 692.9 & -
\end{tabular}

thermally stable than FE in CNT/FE under $\mathrm{N}_{2}$. Furthermore in MCNT/FE, FE near MCNT is considerably more thermally stable than FE in the bulk. FE near MCNT in MCNT/FE to a larger extent is more thermally stable than both FE near CNT and also FE in the bulk in CNT/FE.

It can be concluded that a highly filled FE with MCNT will have a high percentage of FE near or attached to MCNT, which can have thermal stabilities up to $540{ }^{\circ} \mathrm{C}$. Therefore

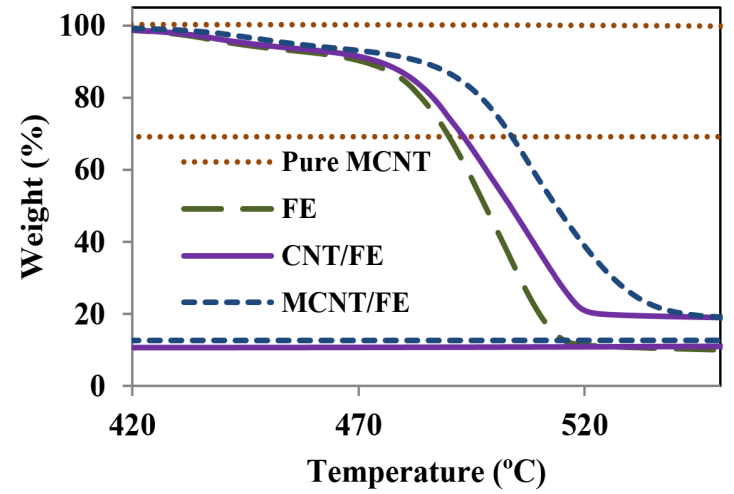

(a)

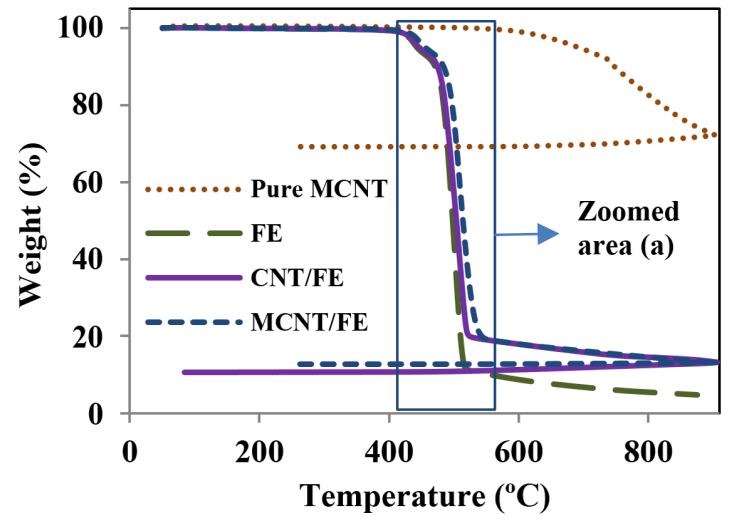

(b)

Figure 1. Heat and cool TGA curves of pure MCNT, FE and filler/FE: (a) zoomed and (b) unzoomed.

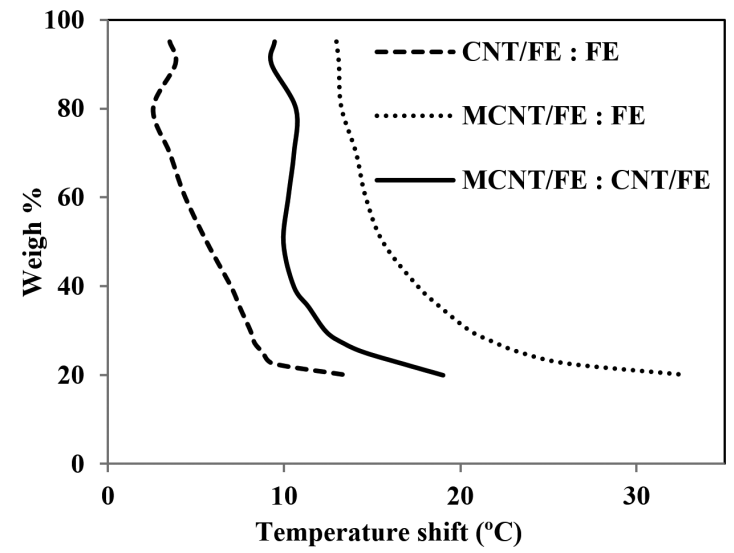

Figure 2. Thermal stability shift curve calculated from TGA curves of FE and filler/FE. 
it is predicted that a highly filled FE with MCNT can stay up to $540{ }^{\circ} \mathrm{C}$.

Figure 2 also shows the amount of this thermal stability shift versus weight $\%$ for $\mathrm{MCNT} / \mathrm{FE}$ relative to $\mathrm{FE}$. Again the $\mathrm{MCNT} / \mathrm{FE}$ curve shifted towards higher temperatures and the thermal stability improved compared to FE. Figure 2 shows that, for the weight $\%$ of 100 to $50 \%$, the amount of thermal stability shift is almost constant $\left(\approx 13-15^{\circ} \mathrm{C}\right)$. However for weight $\%$ between $\approx 20$ to $50 \%$ the thermal stability shift increases gradually $\left(\approx 15-33{ }^{\circ} \mathrm{C}\right)$. This increase in thermal stability shift shows that in this weight $\%$ range compared to the 100 to 50 weight $\%$ range, $\mathrm{FE}$ in $\mathrm{MCNT} / \mathrm{FE}$ has more thermal stability improvement relative to $\mathrm{FE}$ in unfilled FE.

Once more, based on Pham et al. ${ }^{[4]}$ work and the above results it can be concluded that greater thermal stability shift for weight $\%$ between $\approx 20$ to $50 \%$ will be for the part of FE which is near or attached to MCNT. All of the above mentioned results show that FE in MCNT/FE is more thermally stable than FE in unfilled FE under $\mathrm{N}_{2}$. Furthermore in MCNT/FE, FE near MCNT is considerably more thermally stable than FE in the bulk. FE near MCNT in MCNT/FE to a large extent is more thermally stable than FE in unfilled FE.

By comparing the thermal stability improvement of FE in $\mathrm{MCNT} / \mathrm{FE}$ and $\mathrm{CNT} / \mathrm{FE}$, both relative to $\mathrm{FE}$ in unfilled $\mathrm{FE}$, it can be seen that for all weights $\%$ (100 to $\approx 20 \%)$ the thermal stability improvement of FE in MCNT/FE is considerably more than that of CNT/FE.

\subsubsection{TGA: weight of residual}

Figure 1 also shows that with the incorporation of MCNT, a greater amount of the FE remained and produced char preserve in the temperature range of $400-540^{\circ} \mathrm{C}$ compared to $\mathrm{CNT} / \mathrm{FE}$ and FE. This amount was calculated as follows.

Table 2. The percentage of filler remaining in pure filler and filler/FE at different temperatures.

\begin{tabular}{crccc}
\hline Temperature $\left({ }^{\circ} \mathbf{C}\right)$ & MCNT & MCNT/FE & CNT & CNT/FE \\
\hline 520 & 100.00 & 8.40 & 100.00 & 8.4 \\
530 & 99.94 & 8.39 & 100.00 & 8.4 \\
540 & 99.87 & 8.39 & 99.70 & 8.4 \\
560 & 99.67 & 8.37 & 99.30 & 8.3 \\
600 & 99.04 & 8.32 & 97.90 & 8.2 \\
650 & 97.21 & 8.17 & 94.50 & 7.3 \\
700 & 94.39 & 7.93 & 89.30 & 7.5 \\
800 & 82.52 & 6.93 & 66.60 & 5.6 \\
875 & 74.15 & 6.23 & 54.80 & 4.6 \\
\hline
\end{tabular}

The percentage of "MCNT remaining" within the nanocomposite can be calculated by multiplying the percentage of MCNT obtained from the TGA data of pure MCNT at that temperature by 8.4 (the initial percentage of MCNT in FE). These amounts are shown in Table 2. From Figure 1 and Table 2, it can be seen that pure MCNT lost less weight at temperatures up to $900{ }^{\circ} \mathrm{C}$ than pure CNT. Again, in the TGA of the nanocomposite, at each temperature, the percentage of "undegraded FE + char + mineral additives" can be calculated by subtracting the percentage of "MCNT remaining" in the nanocomposite (Table 2) from the percentage of nanocomposite remaining in the TGA curve extrapolated in Figure 1 at that temperature. The results of these calculations are shown in Table 3. This amount, minus the initial mineral filler (2.5\%), gives the percentage of "undegraded FE + char" as recorded in the same table. The same calculations were done for CNT/FE. However, in Table 3 the possible reactions of fillers at high temperatures are not considered.

The results in Table 3 support the finding that, in $\mathrm{MCNT} / \mathrm{FE}$, a greater amount of FE remained and produced char preserve, particularly in the temperature range of 520-540 ${ }^{\circ} \mathrm{C}$, compared to CNT/FE and FE. Therefore, the presence of MCNT enhances the thermal stability of $\mathrm{FE}$, resulting in a higher percentage of the nanocomposite remaining undegraded at higher temperatures compared to $\mathrm{CNT}$ in FE or unfilled FE. Besides, in MCNT/FE and $\mathrm{CNT} / \mathrm{FE}$, most of the char was stable up to $900{ }^{\circ} \mathrm{C}$.

\subsubsection{EDX analysis: residual elemental}

The composition of the residue from the heating-cooling TGA run cycle, as mentioned in the experimental section, was characterized by EDX. The TGA curves of the samples are shown in Figure 3. In the heating-cooling run, the cooling was done with the highest possible cooling rate in order to prevent further degradation and to keep the same composition of the remaining materials at $560{ }^{\circ} \mathrm{C}$ and at $900{ }^{\circ} \mathrm{C}$ upon cooling. Table 4 shows the elemental compositions of the residues in heating-cooling TGA runs for the compounds under study which were extracted from the EDX results (Figures 4 and 5). Figures 4 and 5 also show FESEM images of MCNT/FE- $560{ }^{\circ} \mathrm{C}$ and MCNT/FE- $900{ }^{\circ} \mathrm{C}$ residues respectively.

From Figure 3 it can be seen that, at low temperatures, after a cooling scan of the MCNT/FE-560 ${ }^{\circ} \mathrm{C}$ sample, $19.18 \%$ of the nanocomposite remained. If this amount

Table 3. The percentage of "undegraded FE + char + mineral additives" and "undegraded FE + Char" remained in the compounds at different temperatures.

\begin{tabular}{cccccc}
\hline \multirow{2}{*}{ Temperature $\left({ }^{\circ} \mathbf{C}\right)$} & \multicolumn{2}{c}{ "undegraded FE + char + mineral additives" } & \multicolumn{2}{c}{ "undegraded FE + Char" } \\
\cline { 2 - 6 } & FE & MCNT/FE & CNT/FE & MCNT/FE & CNT/FE \\
\hline 520 & - & 30.58 & 12.56 & 28.08 & 10.06 \\
530 & - & 17.63 & 11.58 & 15.13 & 9.08 \\
540 & - & 12.19 & 10.88 & 9.69 & 8.38 \\
560 & - & 10.54 & 10.48 & 8.04 & 7.98 \\
600 & 7.90 & 9.65 & 9.68 & 7.15 & 7.18 \\
650 & 7.00 & 8.84 & 9.52 & 6.34 & 7.02 \\
700 & 6.10 & 8.24 & 8.32 & 5.74 & 5.82 \\
800 & 4.90 & 7.65 & 8.32 & 5.15 & 5.82 \\
875 & 4.30 & 7.30 & & 5.80 \\
\hline
\end{tabular}


is multiplied by weight $\%$ of each element in Table 4 , the weight $\%$ of that element based on the initial nanocomposite can be obtained. The same procedure was carried out for all

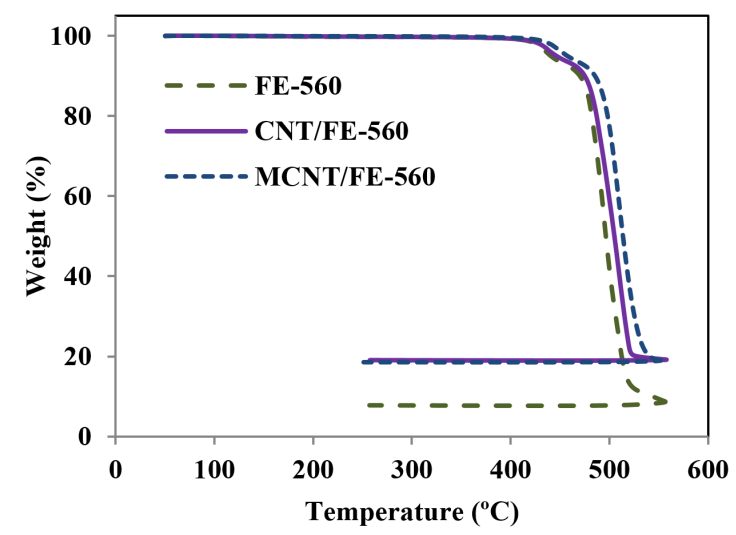

Figure 3. Heat and cool TGA curves of FE and filler/FE up to $560{ }^{\circ} \mathrm{C}$.

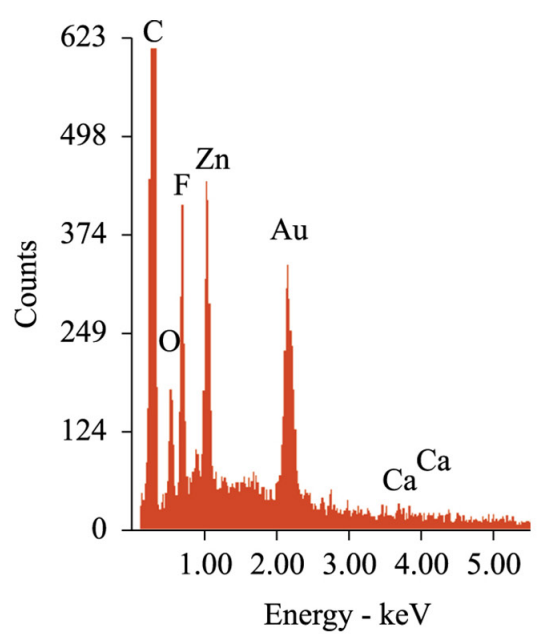

(a)

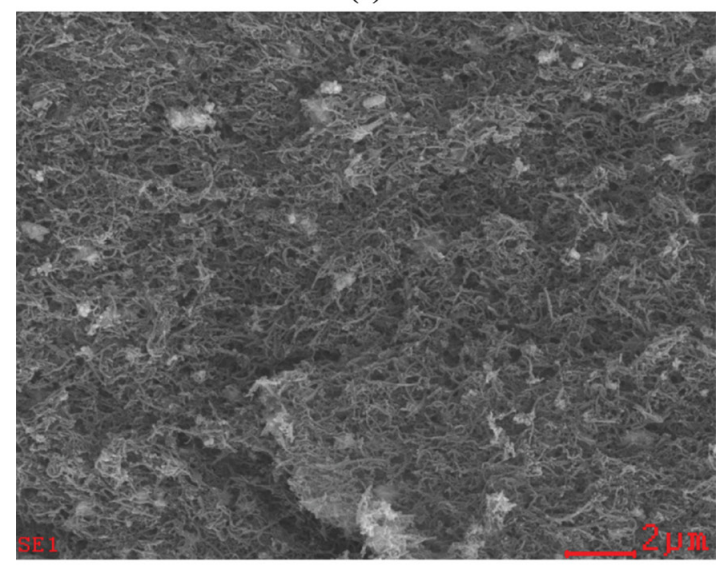

(b)

Figure 4. EDX spectra (a) and FESEM image (b) of $\mathrm{MCNT} / \mathrm{FE}-560^{\circ} \mathrm{C}$. specimens. The results of these calculations are presented in Table 5 .

These results show that the percentage of carbon and fluorine in the residue of the TGA scan of MCNT/FE- $560^{\circ} \mathrm{C}$ are the same as $\mathrm{CNT} / \mathrm{FE}-560^{\circ} \mathrm{C}$. This proves that $\mathrm{MCNT}$ is able to preserve the same amount of FE from degradation compared to the samples containing CNT at this temperature. Similarly, based on the EDX results and considering the work of Pham et al. ${ }^{[4]}$ as mentioned earlier, it can be seen that FE attached to or near MCNT at the higher temperature range exhibits a lower degradation tendency. Considering this and the fact that more carbon and fluorine remained in this nanocomposite residue after the TGA run, it can also be concluded that a greater amount of the FE remained undegraded or less degraded especially near MCNT. The amount of remaining fluorine represents the undegraded FE.

These results also show that the percentage of carbon and fluorine in the residue of the TGA scan of MCNT/FE-560 ${ }^{\circ} \mathrm{C}$ is higher compared to $\mathrm{FE}-560^{\circ} \mathrm{C}$. This proves that MCNT is able to preserve more $\mathrm{FE}$ from degradation compared to the samples containing unfilled FE.

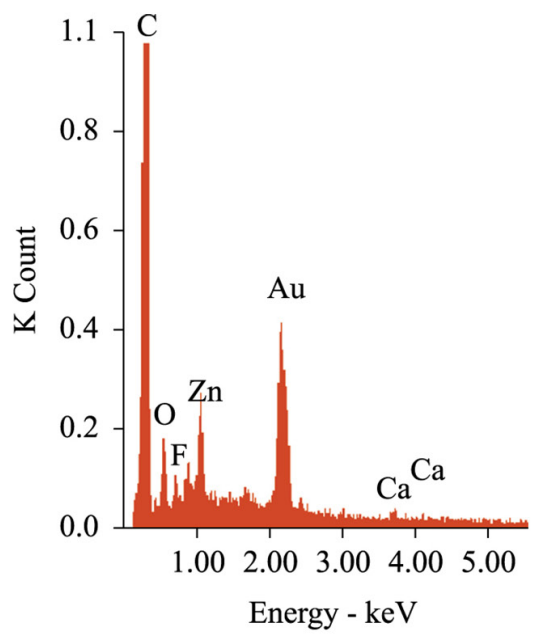

(a)

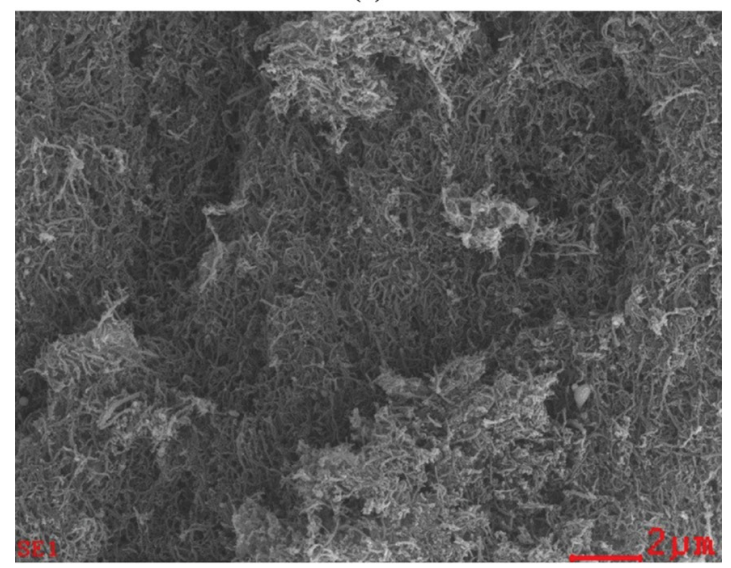

(b)

Figure 5. EDX spectra (a) and FESEM image (b) of MCNT/FE- $900{ }^{\circ} \mathrm{C}$. 
Table 4. The weight $\%(\mathrm{Wt} \%)$ and Atomic $\%$ (At $\%)$ composition of the remaining composites in TGA runs.

\begin{tabular}{|c|c|c|c|c|c|c|c|c|c|c|}
\hline \multirow{2}{*}{ Element } & \multicolumn{2}{|c|}{ FE-560 ${ }^{\circ} \mathrm{C}$} & \multicolumn{2}{|c|}{ MCNT/FE-560 ${ }^{\circ} \mathrm{C}$} & \multicolumn{2}{|c|}{ CNT/FE-560 ${ }^{\circ} \mathrm{C}$} & \multicolumn{2}{|c|}{ MCNT/FE-900 ${ }^{\circ} \mathrm{C}$} & \multicolumn{2}{|c|}{ CNT/FE-900 ${ }^{\circ} \mathrm{C}$} \\
\hline & Wt \% & At $\%$ & Wt $\%$ & At $\%$ & Wt \% & At $\%$ & Wt \% & At $\%$ & Wt $\%$ & At $\%$ \\
\hline $\mathrm{C}$ & 27.16 & 50.48 & 69.78 & 84.46 & 68.98 & 80.89 & 83.87 & 92.01 & 65.42 & 83.62 \\
\hline $\mathrm{O}$ & 14.00 & 19.53 & 5.34 & 4.86 & 10.05 & 8.85 & 6.14 & 5.06 & 8.95 & 8.59 \\
\hline $\mathrm{F}$ & 11.07 & 13.01 & 9.11 & 6.97 & 10.45 & 7.75 & 1.55 & 1.07 & 2.54 & 2.05 \\
\hline $\mathrm{Si}$ & - & - & - & - & 0.46 & 0.23 & - & - & - & - \\
\hline $\mathrm{Ca}$ & 3.05 & 1.70 & 1.45 & 0.53 & 0.83 & 0.29 & 1.20 & 0.40 & 2.11 & 0.81 \\
\hline $\mathrm{Zn}$ & 44.72 & 15.28 & 14.32 & 3.18 & 9.23 & 1.99 & 7.23 & 1.46 & 20.98 & 4.93 \\
\hline Total & 100 & 100 & 100 & 100 & 100 & 80.89 & 100 & 100 & 100 & 100 \\
\hline
\end{tabular}

Table 5. Amount of element remained based on initial weight of compound.

\begin{tabular}{|c|c|c|c|c|c|}
\hline \multirow{2}{*}{ Element } & \multicolumn{5}{|c|}{ Element remained (\%) } \\
\hline & FE-560 ${ }^{\circ} \mathrm{C}$ & MCNT/FE-560 ${ }^{\circ} \mathrm{C}$ & $\mathrm{CNT} / \mathrm{FE}-560^{\circ} \mathrm{C}$ & MCNT/FE-900 ${ }^{\circ} \mathrm{C}$ & $\mathrm{CNT} / \mathrm{FE}-900^{\circ} \mathrm{C}$ \\
\hline $\mathrm{C}$ & 3.42 & 13.38 & 13.13 & 10.69 & 6.26 \\
\hline $\mathrm{F}$ & 0.85 & 1.75 & 2.00 & 0.20 & 0.24 \\
\hline $\mathrm{Zn}$ & 2.08 & 2.75 & 1.76 & 0.92 & 2.00 \\
\hline $\mathrm{Ca}$ & 0.27 & 0.28 & 0.16 & 0.15 & 0.20 \\
\hline $\mathrm{Si}$ & - & - & 0.09 & - & - \\
\hline
\end{tabular}

\subsubsection{EDX analysis: undegraded FE and char}

At $560^{\circ} \mathrm{C}$, the "undegraded FE + char" for MCNT/FE- $560^{\circ} \mathrm{C}$ can also be calculated by subtracting the percentage of "MCNT remaining" in the nanocomposite (Table 2) from the percentage of " $\mathrm{C}+\mathrm{F}$ " in the $\mathrm{EDX}$ analysis at $560^{\circ} \mathrm{C}$. Thus, the percentage of "undegraded FE + char" for MCNT/FE- $560^{\circ} \mathrm{C}$ is 6.76 and for $\mathrm{CNT} / \mathrm{FE}-560^{\circ} \mathrm{C}$ is $6.98 \%$, again showing the same percentage of "undegraded FE + char" as in the case of using MCNT or CNT as filler for FE.

Table 5 also shows that when MCNT/FE- $900{ }^{\circ} \mathrm{C}$ and CNT/FE- $900{ }^{\circ} \mathrm{C}$ were run up to $900{ }^{\circ} \mathrm{C}$, much less fluorine and carbon remained compared to $\mathrm{MCNT} / \mathrm{FE}-560^{\circ} \mathrm{C}$ and $\mathrm{CNT} / \mathrm{FE}-560{ }^{\circ} \mathrm{C}$ respectively. These results indicate that most of the undegraded $\mathrm{FE}$ at temperatures below $560^{\circ} \mathrm{C}$ was degraded from $560^{\circ} \mathrm{C}$ up to $900^{\circ} \mathrm{C}$ in both MCNT/FE and $\mathrm{CNT} / \mathrm{FE}$.

At $900{ }^{\circ} \mathrm{C}$, the "char" for MCNT/FE- $900{ }^{\circ} \mathrm{C}$ can also be calculated by subtracting the percentage of "MCNT remaining" in the nanocomposite (Table 2) from the percentage of " $\mathrm{C}+\mathrm{F}$ " in $\mathrm{EDX}$ analysis at $900^{\circ} \mathrm{C}$. Thus, the percentage of "char" for MCNT/FE- $900{ }^{\circ} \mathrm{C}$ is $3.29 \%$ and for $\mathrm{CNT} / \mathrm{FE}-900{ }^{\circ} \mathrm{C}$ is $1.9 \%$, showing more "char" remained in the case of using MCNT as the filler for FE compared to CNT. Therefore, it can be suggested that in MCNT/FE, more char is stable up to $900^{\circ} \mathrm{C}$ compared to CNT/FE.

Comparison of $\mathrm{Zn} \%$ in $\mathrm{CNT} / \mathrm{FE}-560{ }^{\circ} \mathrm{C}$ and CNT/FE-900 ${ }^{\circ} \mathrm{C}$ (Table 5) shows that the amount of $\mathrm{Zn}$ in $\mathrm{CNT} / \mathrm{FE}$ was almost unchanged and did not undergo any reaction up to $900{ }^{\circ} \mathrm{C}$. On the other hand, the $\mathrm{Zn} \%$ in MCNT/FE-560 ${ }^{\circ} \mathrm{C}$ and MCNT/FE-900 ${ }^{\circ} \mathrm{C}$ shows that a certain amount disappeared up to $900{ }^{\circ} \mathrm{C}$. This is due to the reaction of $\mathrm{ZnO}$ with carbon at high temperatures, producing vaporized $\mathrm{Zn}$. This reaction of $\mathrm{ZnO}$ and $\mathrm{C}$ at high temperatures was reported by Gokon et al. ${ }^{[24]}$.

\subsection{Verifying thermal stability in FE composites}

The increased decomposition temperatures caused by using MCNT in FE are due to several reasons, some of which are the same as those mentioned for $\mathrm{CNT}$ in $\mathrm{FE}^{[4]}$. Firstly, the presence of MCNT in FE makes the active centers of the FE main chains inactive, preventing degradation, therefore saving FE that is nearer to the MCNT surface. Secondly, the interactions between MCNT and FE result in increased physical and chemical cross-linking points which prevent the degradation of the polymer chains. Besides, considering that the degradation of FE is a radical chain reaction, it is therefore susceptible to inhibition by reagents capable of trapping such radicals. Furthermore, the antioxidant nature of MCNT, attributed to its high electron affinity $(\approx 2.65 \mathrm{eV})$, enables it to act as a radical scavenger. Consequently, MCNT helps to trap radicals and inhibits the degradation of FE nearer to it. Moreover, Endo et al. ${ }^{[3]}$ reasoned that the thermal stability of FE near MCNT is due to the presence of bounded rubber to MCNT and concluded that this structure could prevent the decomposition of rubber at high temperatures by resisting molecular mobility.

Wang et al. ${ }^{[25]}$ reported that in $\mathrm{PVDF} / \mathrm{SiO} 2$ - grapheme oxide (GO) composites there is a strong interaction between many of the functional groups in the GO and PVDF chains. In particular, the C-F bond in PVDF and carboxyl or hydroxyl groups of grapheme oxides (GO) in the PVDF/SiO2-GO composites form hydrogen bonds, and this supports the enhancement of interfacial interaction. The same hydrogen bonding can be formed between functional groups in MCNT and C-F of FE. Ma and Larsen ${ }^{[2]}$ also reported that nitric acid treated single wall nanotubes (SWNT) compared to untreated MWNT have better physical surface affinities with PVDF. The same compatibility can be mentioned here between MCNT and FE compared to CNT and FE. Therefore, there is a strong interaction, which is from the hydrogen bonding and compatibility described above, between MCNT and FE, and these interactions are not present between CNT and FE. More interactions between MCNT and FE compared to CNT and FE result in increased physical and chemical cross-linking points, which prevents more degradation of the polymer chains in the case of MCNT/FE. Furthermore, these interactions will increase the amount of bounded rubber to MCNT in MCNT/FE compared to CNT in CNT/FE and, 
as explained above, more bounded rubber will increase the thermal stability in the case of MCNT/FE.

\subsection{Effect of thermal aging on residual elemental composition}

Figure 6 illustrates representative figures of EDX obtained for aged and un-aged samples. The elemental weight percent extracted from these figures is presented in Table 6. This table shows the surface composition of the composites before and after aging. The major elements in the composites are $\mathrm{C}, \mathrm{O}, \mathrm{F}$ and $\mathrm{Si}$. The initial loss in element is defined as the percentage lost due to aging for different periods of time. The percentage loss can be calculated as follows: For $100 \mathrm{~g}$ of un-aged FE (Table 6), there were $34.26,4.99,59.82$ and $0.92 \mathrm{~g}$ of C, O, F and Si respectively. After 72 hours of aging, if $\mathrm{C}_{\text {rem }}, \mathrm{O}_{\text {rem }}$, and $\mathrm{F}_{\text {rem }} \mathrm{g}$ of $\mathrm{C}, \mathrm{O}$ and F respectively remained and $\mathrm{C}_{10 s}, \mathrm{O}_{\text {los }}$ and $\mathrm{F}_{\text {los }}$ g of $\mathrm{C}, \mathrm{O}$ and F respectively were lost. Then;

$$
\begin{aligned}
& C_{r e m}+C_{l o s}=34.26 \mathrm{~g} ; \\
& O_{\text {rem }}+O_{\text {los }}=4.99 \mathrm{~g} \text { and } \\
& F_{\text {rem }}+F_{\text {los }}=59.82 \mathrm{~g}
\end{aligned}
$$

Since $\mathrm{Si}$ is not lost during aging, the amount of $\mathrm{Si}$ after 72 hours of aging is $0.92 \mathrm{~g}$. If $\mathrm{T}$ is the total weight of the remaining elements, then; $\mathrm{T}=\mathrm{C}_{\mathrm{rem}}+\mathrm{O}_{\text {rem }}+\mathrm{F}_{\text {rem }}+0.92 \mathrm{~g}$

After 72 hours of aging, the weight percentage of $\mathrm{Si}$ is $2.32 \%$ (Table 6), therefore; $\frac{0.92}{T}=0.0232$, and thus $\mathrm{T}=39.66 \mathrm{~g}$. Using $\mathrm{T}$ and the percentage of $\mathrm{C}$ (Table 6), after 72 hours of aging $(30.89 \%), \mathrm{C}_{\mathrm{rem}}$ can be calculated as, $0.3089=\frac{C_{r e m}}{T}$. Thus, $\mathrm{C}_{\text {rem }}=0.3089 \times 39.66=12.25 \mathrm{~g}$. $\mathrm{C}_{\text {los }}=34.26-\mathrm{C}_{\mathrm{rem}}=22.01 \mathrm{~g}$. Therefore, the percentage of $\mathrm{C}_{\mathrm{los}}$ is,

$$
\begin{aligned}
& C_{\text {los }}(\%)=\frac{\text { Wt.of } C_{\text {los }}}{\text { Wt.ofinitialC }} \times 100(\%)= \\
& \frac{22.01}{34.26} \times 100(\%)=64.24 \%
\end{aligned}
$$

This means $64.24 \%$ of the initial $\mathrm{C}$ was removed from the surface after 72 hours of aging at $250{ }^{\circ} \mathrm{C}$. The same calculations were done for $\mathrm{F}$ and $\mathrm{O}$ in all other aged composites. The results of these calculations are presented in Table 7. These results show that for each composite, with increasing aging time, the percentage loss of $\mathrm{C}, \mathrm{O}$ and $\mathrm{F}$ increased. This is because, as the aging time increased, more degradation including dehydrofluorination, defluorination and carbon oxygen reactions occurred especially at the surface $^{[27]}$. The results also show that at each aging time, for $\mathrm{CNT} / \mathrm{FE}$ the loss of elements was lower than for MCNT/FE. Therefore, CNT can preserve a larger portion of the elastomer surface from degradation compared to MCNT.

For CNT/FE, up to 24 hours of aging, the initial percentage loss of each element slightly increased. Nevertheless, as the aging time increased, even a decrease in percentage loss was observed. This means that the slight degradation happened mainly in the first 24 hours and did not increase after that. For MCNT/FE, up to 24 hours of aging, the same trend as with CNT/FE was observed. However, as the aging time increased, there was a drastic increase in percentage loss. FE underwent thermal oxidation and dehydrofluorination during hot air aging ${ }^{[27]}$. Due to the dehydrofluorination reaction, $\mathrm{HF}$ was produced ${ }^{[27]}$ and the carboxylic acidic groups on the surface of MCNT reacted with HF. Wang et al. ${ }^{[28]}$ reported a similar reaction between dispersed graphene oxide (GO) and hydrofluoric acid (HF) during the synthesis of fluorinated grapheme sheets (FGS). The authors mentioned that fluorine was grafted onto the basal plane of graphene. Furthermore, the oxygen-containing groups in GO played a major role in FGS formation, and the fluorination degree could be easily controlled by varying the reaction temperature, times and amounts of HF. They also stated that fluorination

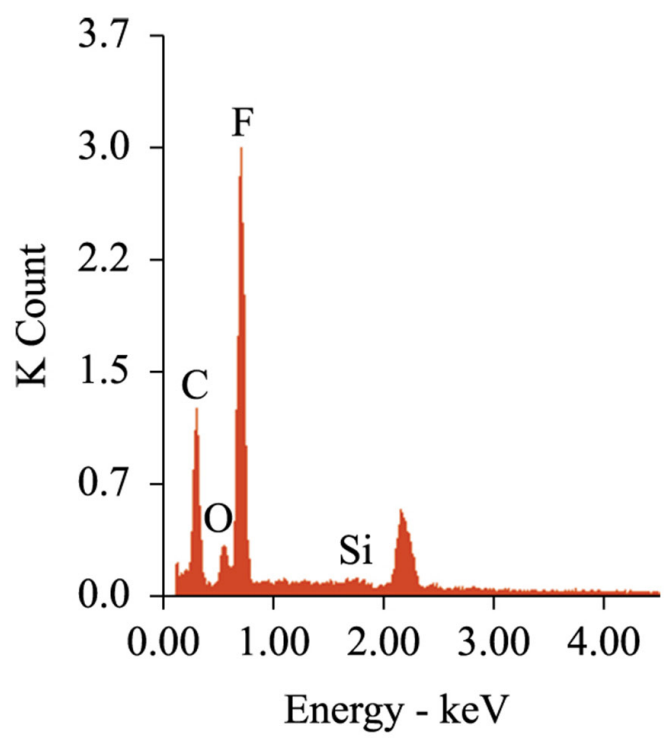

(a)

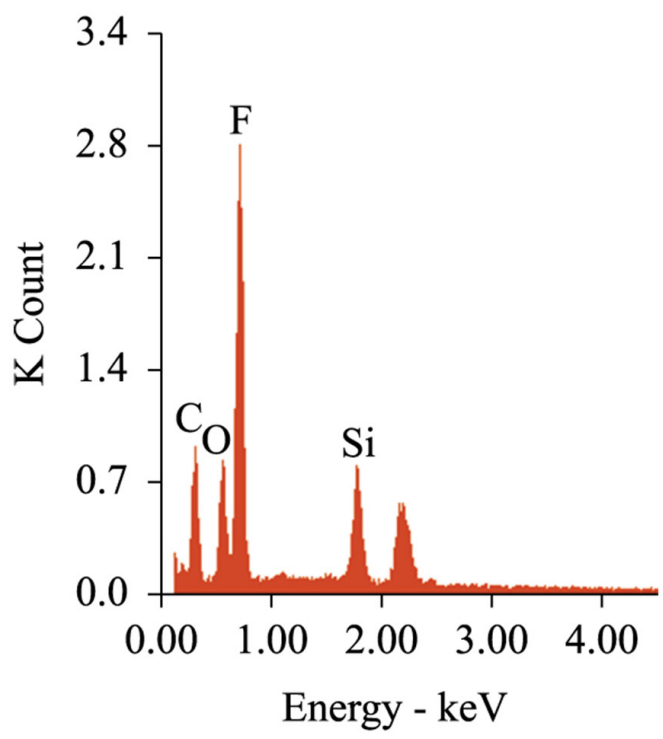

(b)

Figure 6. EDX spectra of (a) MCNT/FE and (b) MCNT/FE-72. 
Table 6. The surface composition of the composites before and after aging, obtained by EDX.

\begin{tabular}{|c|c|c|c|c|c|c|c|c|}
\hline \multirow{2}{*}{ Element } & Wt \% & At \% & Wt \% & At $\%$ & Wt \% & At $\%$ & Wt \% & At $\%$ \\
\hline & \multicolumn{2}{|c|}{ FE } & \multicolumn{2}{|c|}{ FE-24 } & \multicolumn{2}{|c|}{ FE-48 } & \multicolumn{2}{|c|}{ FE-72 } \\
\hline $\mathrm{C}$ & 34.26 & 44.95 & - & - & 30.65 & 41.04 & 30.89 & 41.37 \\
\hline $\mathrm{O}$ & 4.99 & 4.92 & - & - & 3.94 & 3.96 & 04.75 & 04.78 \\
\hline $\mathrm{F}$ & 59.82 & 49.62 & - & - & 64.02 & 54.20 & 62.03 & 52.52 \\
\hline $\mathrm{Si}$ & 0.92 & 0.52 & - & - & 1.40 & 0.80 & 2.32 & 1.33 \\
\hline Total & 100 & 100 & - & - & 100 & 100 & 100 & 100 \\
\hline Element & \multicolumn{2}{|c|}{ MCNT/FE } & \multicolumn{2}{|c|}{ MCNT/FE-24 } & \multicolumn{2}{|c|}{ MCNT/FE-48 } & \multicolumn{2}{|c|}{ MCNT/FE-72 } \\
\hline $\mathrm{C}$ & 34.06 & 44.64 & 30.46 & 40.63 & 31.46 & 42.11 & 26.58 & 36.95 \\
\hline $\mathrm{O}$ & 6.41 & 06.31 & 7.36 & 7.37 & 7.07 & 7.10 & 12.95 & 13.51 \\
\hline F & 58.5 & 48.48 & 60.51 & 51.04 & 56.99 & 48.23 & 47.77 & 41.99 \\
\hline $\mathrm{Si}$ & 1.02 & 0.57 & 1.68 & 0.96 & 4.48 & 2.56 & 12.69 & 7.55 \\
\hline Total & 100.00 & 100.00 & 100.00 & 100.00 & 100.00 & 100.00 & 100.00 & 100.00 \\
\hline Element & \multicolumn{2}{|c|}{ CNT/FE } & \multicolumn{2}{|c|}{ CNT/FE-24 } & \multicolumn{2}{|c|}{ CNT/FE-48 } & \multicolumn{2}{|c|}{ CNT/FE-72 } \\
\hline $\mathrm{C}$ & 35.43 & 46.32 & 36.75 & 47.92 & 31.99 & 42.60 & 30.90 & 41.39 \\
\hline $\mathrm{O}$ & 3.60 & 3.53 & 2.79 & 2.70 & 3.53 & 3.53 & 3.69 & 3.71 \\
\hline F & 59.99 & 49.60 & 58.56 & 48.32 & 62.92 & 52.98 & 63.63 & 53.89 \\
\hline $\mathrm{Si}$ & 0.98 & 0.55 & 1.91 & 1.07 & 1.56 & 0.89 & 1.78 & 1.02 \\
\hline Total & 100 & 100 & 100 & 100 & 100 & 100 & 100 & 100 \\
\hline
\end{tabular}

occurred at the original $\mathrm{sp}^{3} \mathrm{C}$ sites in $\mathrm{GO}$, that is, the $\mathrm{C}$ sites connected with the oxygen-containing groups. In the case of MCNT/FE, this reaction caused increased degradation particularly at aging times higher than 24 hours, leading to more loss of $\mathrm{F}$ and $\mathrm{C}$ from the surface compared to $\mathrm{CNT} / \mathrm{FE}$.

Comparing the results of $\mathrm{FE}$ and MCNT/FE at aging times longer than 24 hours, it can also be seen that for FE without MCNT, the loss of elements was lower than for FE with MCNT. This could be due to the same reasons as those given above in the comparison of MCNT/FE and CNT/FE.

The reasons adduced for the saving of a higher percentage of undegraded FE and char in the TGA runs are also valid for the thermal aging of MCNT/FE in the first 24 hours. Besides, the antioxidant nature of MCNT enables it to act as a radical scavenger ${ }^{[4]}$ especially for the oxide radicals produced due to the presence of air. This also helps to trap radicals, thereby inhibiting the degradation of nearby MCNT, and results in an increased percentage of undegraded FE.

A considerable depletion of $\mathrm{F}$ and $\mathrm{C}$ on the surface and to a depth of around 10-15 $\mu \mathrm{m}$ of the cross-section of the $\mathrm{CB} / \mathrm{FE}$ seals aged in oil containing amine based dispersant at $150{ }^{\circ} \mathrm{C}$ was also reported by Smith et al. ${ }^{[22]}$. They also reported the catalytic effect of amine on the degradation of FE. The authors reported that polytetrafluoroethylene (PTFE) also began to soften and release $\mathrm{F}$ at around $200-220^{\circ} \mathrm{C}$. This may explain the apparent susceptibility to heating in air shown by elastomers with a high TFE content. A drastic decrease in $\mathrm{C}$ and $\mathrm{F}$ due to thermal aging in air at $200{ }^{\circ} \mathrm{C}$ from the surface of $\mathrm{CB} / \mathrm{FE}$ (up to a depth of $5 \mathrm{~nm}$ ) was also reported by Wang et al. ${ }^{[27]}$.

Figure 7 shows the FESEM image of MCNT/FE razor cut surfaces. The very good distribution and dispersion of $\mathrm{MCNT}$ in FE can be seen in this figure.

\subsection{Other works on FE and fillers/FE}

In our before study ${ }^{[29]}$, we verified the crystalinity of some of the above mentioned FE and fillers/FE, by Dynamic mechanical analysis (DMA), Differential Scanning Calorimetry
Table 7. Initial element loss percentage after aging compared to un-aged samples.

\begin{tabular}{cccc}
\hline \multirow{2}{*}{ Element } & \multicolumn{3}{c}{ Initial Element loss\% } \\
\cline { 2 - 4 } & FE-24 & FE-48 & FE-72 \\
\hline $\mathrm{C}$ & - & 41.21 & 64.25 \\
$\mathrm{O}$ & - & 48.11 & 62.25 \\
$\mathrm{~F}$ & - & 29.67 & 58.88 \\
$\mathrm{Si}$ & - & 0 & 0 \\
\hline Element & MCNT/FE-24 & MCNT/FE-48 & MCNT/FE-72 \\
\hline $\mathrm{C}$ & 45.70 & 78.97 & 93.73 \\
$\mathrm{O}$ & 30.29 & 74.89 & 83.76 \\
$\mathrm{~F}$ & 37.20 & 77.82 & 93.44 \\
$\mathrm{Si}$ & 0 & 0 & 0 \\
\hline Element & $\mathbf{C N T} / \mathbf{F E}-24$ & $\mathbf{C N T} / \mathbf{F E}-48$ & $\mathbf{C N T} / \mathbf{F E - 7 2}$ \\
\hline $\mathrm{C}$ & 46.73 & 43.28 & 51.98 \\
$\mathrm{O}$ & 60.19 & 38.40 & 43.57 \\
$\mathrm{~F}$ & 49.86 & 34.11 & 41.60 \\
$\mathrm{Si}$ & 0 & 0 & 0 \\
\hline
\end{tabular}

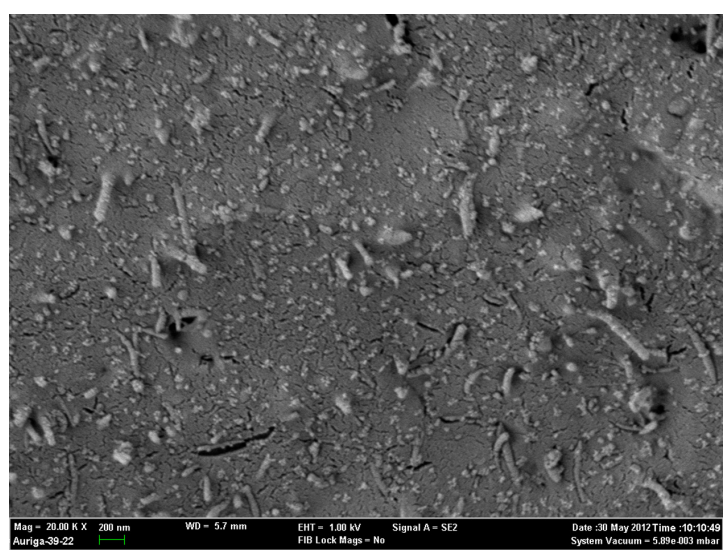

Figure 7. FESEM image of MCNT/FE (the razor cut cross section surface).

(DSC) and X-ray diffraction (XRD). Verifying thermal properties of fluoroelastomer using carbon nanotubes in presence of air and under nitrogen flow is the other study ${ }^{[30]}$. 


\section{Conclusions}

TGA shows that the thermal stability of FE in a $\mathrm{N}_{2}$ atmosphere increased with the presence of MCNT relative to when either CNT was used or while FE was unfilled. A higher percentage of this composite in the form of undegraded $\mathrm{FE}$ or char remained within the temperature range of $400-900{ }^{\circ} \mathrm{C}$ compared to CNT/FE or FE. The MCNT/FE TGA curve shifted towards higher temperatures compared to CNT/FE or FE. The same results also revealed that a higher percentage of FE was undegraded or less degraded especially near MCNT in the temperature range of $400-540{ }^{\circ} \mathrm{C}$.

EDX analysis shows that the percentage of carbon and fluorine in the residue of TGA runs up to $560{ }^{\circ} \mathrm{C}$ of $\mathrm{MCNT} / \mathrm{FE}$ was the same as $\mathrm{CNT} / \mathrm{FE}$ and higher than that of FE. EDX of the residue of TGA runs up to $900{ }^{\circ} \mathrm{C}$ shows that most of the undegraded $\mathrm{FE}$ which was not degraded at temperatures up to $560^{\circ} \mathrm{C}$ was degraded from $560^{\circ}$ up to $900^{\circ} \mathrm{C}$ in both MCNT/FE and CNT/FE. However, the char in $\mathrm{MCNT} / \mathrm{FE}$ was more than that in $\mathrm{CNT} / \mathrm{FE}$ at $900{ }^{\circ} \mathrm{C}$.

The EDX results of aged specimens under air indicate that the percentage of $\mathrm{C}, \mathrm{F}$ and $\mathrm{O}$ lost on the surface of filler/FE and $\mathrm{FE}$ increased with increasing aging time. Again, at 24 hour aging time, MCNT preserved a higher percentage of these elements compared to CNT. The order of percentage loss in elements after 24 hour aging time was $\mathrm{MCNT} / \mathrm{FE}>\mathrm{FE}>\mathrm{CNT} / \mathrm{FE}$.

\section{Acknowledgements}

We thank the University of Malaya as the work reported in this paper was funded under the grant numbers UMRG (RG322-15AFR) and BKP (BK005-2014).

\section{References}

1. PSP Global. Comparison of general use and high performance grades of Viton. Colorado. Technical Data Sheet. Retrieved in 14 January 2015, from http://www.pspglobal.com/nfVitongrades. html.

2. Fuller, R. E. (2006). Advanced polymer architecture sealing solutions for oil and gas applications. Sealing Technology, 2006(9), 6-11. http://dx.doi.org/10.1016/S1350-4789(06)713563.

3. Endo, M., Noguchi, T., Ito, M., Takeuchi, K., Hayashi, T., Kim, Y. A., Wanibuchi, T., Jinnai, H., Terrones, M., \& Dresselhaus, M. S. (2008). Extreme-performance rubber nanocomposites for probing and excavating deep oil resources using multi-walled carbon nanotubes. Advanced Functional Materials, 18(21), 3403-3409. http://dx.doi.org/10.1002/adfm.200801136.

4. Pham, T. T., Sridhar, V., \& Kim, J. K. (2009). FluoroelastomerMWNT nanocomposites-1: Dispersion, morphology, physicomechanical, and thermal properties. Polymer Composites, 30(2), 121-130. http://dx.doi.org/10.1002/pc.20521.

5. Ito, M., Noguchi, T., Ueki, H., Takeuchi, K., \& Endo, M. (2011). Carbon nanotube enables quantum leap in oil recovery. Materials Research Bulletin, 46(9), 1480-1484. http://dx.doi. org/10.1016/j.materresbull.2011.04.028.

6. He, L., Xu, Q., Hua, C., \& Song, R. (2010). Effect of multi-walled carbon nanotubes on crystallization, thermal, and mechanical properties of poly(vinylidene fluoride). Polymer Composites, 31(5), 921-927. http://dx.doi.org/10.1002/pc.20876.
7. Chae, D. W., \& Hong, S. M. (2011). Rheology, crystallization behavior under shear, and resultant morphology of PVDF/ multiwalled carbon nanotube composites. Macromolecular Research, 19(4), 326-331. http://dx.doi.org/10.1007/s13233011-0403-1.

8. Levi, N., Czerw, R., Xing, S., Iyer, P., \& Carroll, D. L. (2004). Properties of polyvinylidene difluoride-carbon nanotube blends. Nano Letters, 4(7), 1267-1271. http://dx.doi.org/10.1021/ n10494203.

9. He, L., Sun, J., Zheng, X., Xu, Q., \& Song, R. (2011). Effect of multiwalled carbon nanotubes on crystallization behavior of poly (vinylidene fluoride) in different solvents. Journal of Applied Polymer Science, 119(4), 1905-1913. http://dx.doi. org/10.1002/app.32907.

10. Xu, Y., Zheng, W.-T., Yu, W.-X., Hua, L.-G., Zhang, Y.-J., \& Zhao, Z.-D. (2010). Crystallization behavior and mechanical properties of poly (vinylidene fluoride)/multi-walled carbon nanotube nanocomposites. Chemical Research in Chinese Universities, 26(3), 491.

11. Mago, G., Fisher, F. T., \& Kalyon, D. M. (2009). Deformationinduced crystallization and associated morphology development of carbon nanotube-PVDF nanocomposites. Journal of Nanoscience and Nanotechnology, 9(5), 3330-3340. http:// dx.doi.org/10.1166/jnn.2009.VC08. PMid:19453012.

12. Chen, W., Li, F., Han, G., Xia, J., Wang, L., Tu, J., \& Xu, Z. (2003). Tribological behavior of carbon-nanotube-filled PTFE composites. Tribology Letters, 15(3), 275-278. http://dx.doi. org/10.1023/A:1024869305259.

13. Sementsov, Y. I., Gavrilyuk, N., Prikhod'ko, G., Melezhyk, A., Pyatkovsky, M., Yanchenko, V., Revo, S., Ivanenko, E., \& Senkevich, A. (2007). Properties of PTFE-MWNT composite materials. In, Hydrogen materials science and chemistry of carbon nanomaterials. Netherlands: Springer. p. 757-763.

14. Yu, S., Zheng, W., Yu, W., Zhang, Y., Jiang, Q., \& Zhao, Z. (2009). Formation mechanism of $\beta$-phase in PVDF/CNT composite prepared by the sonication method. Macromolecules, 42(22), 8870-8874. http://dx.doi.org/10.1021/ma901765j.

15. Mago, G., Kalyon, D. M., \& Fisher, F. T. (2008). Membranes of polyvinylidene fluoride and PVDF nanocomposites with carbon nanotubes via immersion precipitation. Journal of Nanomaterials, 2008(17), 1-8. http://dx.doi.org/10.1155/2008/759825.

16. Huang, S., Yee, W. A., Tjiu, W. C., Liu, Y., Kotaki, M., Boey, Y. C. F., Ma, J., Liu, T., \& Lu, X. (2008). Electrospinning of polyvinylidene difluoride with carbon nanotubes: synergistic effects of extensional force and interfacial interaction on crystalline structures. Langmuir, 24(23), 13621-13626. http:// dx.doi.org/10.1021/la8024183. PMid:18956851.

17. Wen, R., Ke, K., Wang, Y., Yang, W., Xie, B.-H., \& Yang, M.B. (2011). Interfacial interaction of polyvinylidene fluoride/ multiwalled carbon nanotubes nanocomposites: A rheological study. Journal of Applied Polymer Science, 121(5), 3041-3046. http://dx.doi.org/10.1002/app.33927.

18. Park, E., Hong, S., Park, D., \& Shim, S. (2010). Preparation of conductive PTFE nanocomposite containing multiwalled carbon nanotube via latex heterocoagulation approach. Colloid \& Polymer Science, 288(1), 47-53. http://dx.doi.org/10.1007/ s00396-009-2120-2.

19. Carabineiro, S. A., Pereira, M. F., Pereira, J. N., Caparros, C., Sencadas, V., \& Lanceros-Mendez, S. (2011). Effect of the carbon nanotube surface characteristics on the conductivity and dielectric constant of carbon nanotube/poly(vinylidene fluoride) composites. Nanoscale Research Letters, 6(1), 302. http://dx.doi.org/10.1186/1556-276X-6-302. PMid:21711832.

20. Carabineiro, S., Pereira, M., Nunes-Pereira, J., Silva, J., Caparros, C., Sencadas, V., \& Lanceros-Méndez, S. (2012). The effect of nanotube surface oxidation on the electrical 
properties of multiwall carbon nanotube/poly (vinylidene fluoride) composites. Journal of Materials Science, 47(23), 8103-8111. http://dx.doi.org/10.1007/s10853-012-6705-7.

21. Xu, T., \& Yang, J. (2012). Effects of surface modification of MWCNT on the mechanical and electrical properties of fluoro elastomer/MWCNT nanocomposites. Journal of Nanomaterials, 2012, 1-9. http://dx.doi.org/10.1155/2012/275637.

22. Smith, G., Park, D., Titchener, K., Davies, R., \& West, R. (1995). Surface studies of oil-seal degradation. Applied Surface Science, 90(3), 357-371. http://dx.doi.org/10.1016/01694332(95)00165-4.

23. Heidarian, J., Hassan, A., \& Lafia-Araga, R. A. (2015). Improving the thermal properties of fluoroelastomer (Viton GF-600S) using carbon nanotube. Polímeros Ciência e Tecnologia, Submitted.

24. Gokon, N., Hasegawa, N., Kaneko, H., Aoki, H., Tamaura, Y., \& Kitamura, M. (2003). Photocatalytic effect of $\mathrm{ZnO}$ on carbon gasification with $\mathrm{CO} 2$ for high temperature solar thermochemistry. Solar Energy Materials and Solar Cells, 80(3), 335-341. http://dx.doi.org/10.1016/j.solmat.2003.08.016.

25. Wang, J., Chen, P., Chen, L., Wang, K., Deng, H., Chen, F., Zhang, Q., \& Fu, Q. (2012). Preparation and properties of poly (vinylidene fluoride) nanocomposites blended with graphene oxide coated silica hybrids. Express Polymer Letters, 6(4), 299-307. http://dx.doi.org/10.3144/expresspolymlett.2012.33.
26. Ma, J., \& Larsen, R. M. (2012). Use of Hansen solubility parameters to predict dispersion and strain transfer of functionalized single-walled carbon nanotubes in poly(vinylidene fluoride) composites. Journal of Thermoplastic Composite Materials, 27(6), 801-815. http://dx.doi.org/10.1177/0892705712455036.

27. Wang, Y., Liu, L., Luo, Y., \& Jia, D. (2009). Aging behavior and thermal degradation of fluoroelastomer reactive blends with poly-phenol hydroxy EPDM. Polymer Degradation \& Stability, 94(3), 443-449. http://dx.doi.org/10.1016/j. polymdegradstab.2008.11.007.

28. Wang, Z., Wang, J., Li, Z., Gong, P., Liu, X., Zhang, L., Ren, J., Wang, H., \& Yang, S. (2012). Synthesis of fluorinated graphene with tunable degree of fluorination. Carbon, 50(15), 5403-5410. http://dx.doi.org/10.1016/j.carbon.2012.07.026.

29. Heidarian, J., \& Hassan, A. (2014). Microstructural and thermal properties of fluoroelastomer/carbon nanotube composites. Composites. Part B, Engineering, 58, 166-174. http://dx.doi. org/10.1016/j.compositesb.2013.10.054.

30. Heidarian, J., \& Hassan, A. (2015). Improving thermal properties of fluoroelastomer using carbon nanotubes in presence of air and under nitrogen flow. Asian Journal of Chemistry, 27(4), 1235-1239. http://dx.doi.org/10.14233/ajchem.2015.17200.

Received: Dec. 27, 2014

Accepted: Apr. 29, 2015 